\title{
PENGARUH PERSEPSI HARGA, BRAND IMAGE DAN PENGALAMAN BELANJA ONLINE TERHADAP PURCHASE DECISION PRODUCT FASHION DI KALANGAN MILENIAL DI JAKARTA
}

\author{
Riski Rahmayanti \\ Program Studi Magister Manajemen Universitas Tarumanagara \\ riskyrama77@gmail.com
}

Masuk : 05-12-2020, revisi : 17-12-2020, diterima untuk diterbitkan : 18-12-2020

\begin{abstract}
The purpose of this study was to determine the effect of Price Perception, Brand Image, and Online Shopping Experience on the Purchase decision of fashion products in millennial Jakarta. Data were collected by distributing questionnaires to 120 respondents, the data were processed using SPSS version 24.0. The results of the study provided empirical evidence that price perceptions partially have a positive and significant effect on purchasing decisions, brand image partially has a positive and significant effect on purchasing decisions, the online shopping experience partially has a positive and significant effect on purchasing decisions, and price perspective, brand image online shopping experience simultaneously has a positive and significant effect on purchasing decisions. This study provides input to academics and fashion companies on how to improve purchasing decisions.
\end{abstract}

Keywords: Brand Image, Price Perception, Online Shopping Experience, Purchase Decision

\begin{abstract}
Abstrak: Tujuan penelitian ini adalah untuk mengetahui pengaruh Persepsi Harga, Brand Image, dan pengalaman berbelanja online terhadap Purchase decision produk fashion di kalangan milenial Jakarta. Pengambilan data dilakukan dengan melakukan penyebaran kuesioner kepada 120 orang, data diolah menggunakan SPSS versi 24.0. Hasil penelitian memberikan bukti empiris bahwa persepsi harga secara parsial berpengaruh positif dan signifikan terhadap keputusan pembelian, brand image secara parsial berpengaruh positif dan signifikan terhadap keputusan pembelian, pengalaman belanja online secara parsial berpengaruh positif dan signifikan terhadap keputusan pembelian, dan persepsi harga, brand image dan pengalaman belanja online secara simultan berpengaruh positif dan signifikan terhadap keputusan pembelian. Penelitian ini memberikan masukan kepada akademisi dan perusahaan fashion bagaimana meningkatkan keputusan pembelian.
\end{abstract}

Kata Kunci: Citra Merek, Persepsi Harga, Pengalaman Belanja Online, Keputusan Pembelian

\section{PENDAHULUAN}

Melihat perkembangan pembelian produk fashion di atas secara tidak langsung menyatakan bahwa milenial menjadi potensi besar sebagai target konsumen yang cocok bagi pelaku industri fashion. Dengan begitu, penting untuk meninjau lebih lanjut karakteristik milenial dalam menentukan keputusannya dalam berbelanja.

Penting bagi pemasar untuk memahami dan mengikuti perkembangan zaman mengenai faktor apa saja yang dapat mempengaruhi konsumen (milenial) dalam memutuskan membeli suatu produk atau keputusan pembelian.

Penelitian ini dilakukan untuk menguji secara empiris pengaruh brand image, persepsi harga, dan pengalaman berbelanja online terhadap keputusan pembelian dalam membeli produk fashion pada generasi milenial di Jakarta. 


\section{TELAAH KEPUSTAKAAN}

\section{Price Perception}

Menurut Chang dan Wildt dalam Kaura (2012) mendefinisikan persepsi harga sebagai "representation of consumer perception or subjective perception of the objective price of the product.". Dapat disimpulkan bahwa persepsi harga adalah suatu proses persepsi konsumen dalam menginterprestasikan harga dan nilai atribut untuk mendapatkan suatu hasil yang dapat diterima dalam suatu kewajaran masuk akal.

\section{Brand image}

Definisi brand image menurut Kotler dan Keller (2012, p. 346) adalah: "The perceptions and beliefs held by consumers, as reflected in the associations held in consumer memory". Disimpulkan bahwa citra merek adalah asosiasi atau kepercayaan yang ada dalam benak konsumen untuk menjadi pembeda dari merek yang lainnya seperti lambang, desain huruf atau warna khusus.

\section{Online Shopping Experience}

Michaud-Trevinal dan Stenger (2014) mendefinisikan online shoping experience bukan bagian dari pengalaman masa lalu, namun sebagai pengalaman sebenarnya yang dirasakan konsumen ketika mereka berbelanja online.

\section{Purchase decision}

Menurut Peter dan Olson (2014, p. 163), keputusan pembelian adalah "The integration process used to combine knowledge to evaluate two or more alternative behaviors and choose one of them". Terdapat 5 (lima) tahapan yaitu problem recognition, information search, evaluation of alternatives, purchase decision, postpurchase behavior dalam proses keputusan pembelian konsumen.

\section{Kaitan antara Persepsi Harga terhadap Purchase decision}

Berdasarkan penelitian Suhaily dan Darmoso (2017) menunjukkan jika persepsi harga berpengaruh signifikan dan positif dalam pengambilan keputusan untuk membeli suatu produk. Dalam penelitian ini juga mengatakan jika persepsi harga merupakan elemen termudah dalam program pemasaran untuk disesuaikan. Persepsi harga menjadi salah satu penilaian bagi konsumen dalam menentukan keputusan pembeliannya, semakin baik persepsi harga terhadap suatu merek maka semakin positif pula keputusan pembelian terjadi.

$\mathrm{H}_{1} \quad$ : Persepsi harga berpengaruh positif terhadap purchase decision produk fashion pada generasi milenial Jakarta

\section{Kaitan antara Brand image terhadap Purchase decision}

Berdasarkan penelitian Foster (2016), menyimpulkan bahwa variabel citra merek berpengaruh positif terhadap keputusan pembelian. Penelitian lainnya oleh Harwani dan Pradita (2017) menunjukkan bahwa brand image memiliki pengaruh yang positif dan signifikan terhadap keputusan pembelian. Semakin positif citra merek dari suatu produk atau perusahaan maka semakin tinggi pula keputusan pembelian konsumen terhadap suatu produk atau merek.

$\mathrm{H}_{2}$ : Citra Merek berpengaruh positif terhadap purchase decision produk fashion pada generasi milenial Jakarta

\section{Kaitan antara pengalaman belanja online terhadap Purchase decision}

Berdasarkan hasil penelitian Kartika dan Ganarsih (2019) menyatakan jika variabel online shopping experience memiliki pengaruh positif dan signifikan terhadap keputusan pembelian e-commerce Shopee. Pengalaman belanja online yang baik akan membuat konsumen lebih memiliki rasa percaya diri yang baik (atau keyakinan yang tinggi) dalam memutuskan untuk membeli sebuah produk.

$\mathrm{H}_{3}$ : Pengalaman belanja online berpengaruh positif terhadap purchase decision produk fashion pada generasi milenial Jakarta 
Berdasarkan uraian kaitan antara variabel-variabel penelitian di atas, maka model penelitian adalah sebagai berikut:

\section{Gambar 1 \\ Model Penelitian}

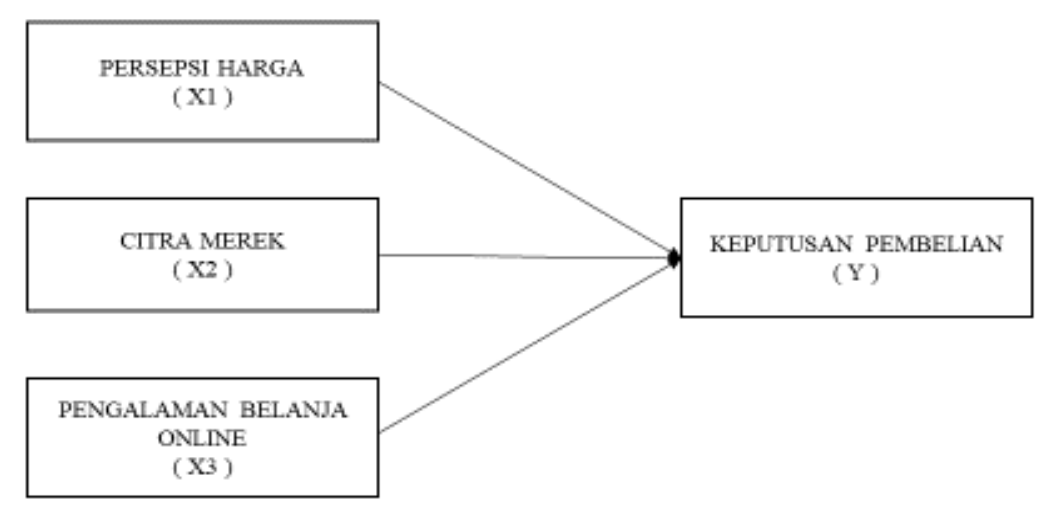

\section{METODOLOGI PENELITIAN}

Desain dalam penelitian ini adalah desain penelitian deskriptif. Sementara pendekatan penelitian deskriptif dalam penelitian ini adalah pendekatan cross-sectional. Periode penelitian dilakukan selama periode tahun 2020.

Penghitungan jumlah sampel yang digunakan dalam penelitian ini didasarkan pada pendapat Aritonang (2014) bahwa sampel sebesar 100-200 termasuk cukup untuk kebanyakan tujuan. Peneliti memutuskan untuk menggunakan sampel minimal sebanyak 120 responden. Sumber data dalam penelitian ini menggunakan sumber data primer (primary data). Metode pengumpulan data dalam penelitian ini dikumpulkan dengan cara melakukan penyebaran menggunakan kuesioner kepada kalangan generasi milenial yang membeli produk fashion online $H \& M$ di Jakarta.

Data mengenai usia 20-24 tahun sebanyak 34 orang responden yang berusia 25-29 tahun sebanyak 61 orang, responden yang berusia 30-34 tahun sebanyak 13 orang, responden yang berusia 35-39 tahun sebanyak 10 orang dan responden yang berusia 40 tahun keatas sebanyak 2 orang. Data mengenai jenis kelamin laki-laki sebanyak 55 orang dengan persentase sebesar $45,8 \%$ sedangkan responden yang berjenis kelamin perempuan sebanyak 65 orang dengan persentase sebesar 54,2\%. Data mengenai jenis pendidikannya SMA sebanyak 21 orang dengan persentase sebesar $17,5 \%$, responden yang jenis pendidikannya D3 sebanyak 8 orang dengan persentase sebesar $6,7 \%$, responden yang jenis pendidikannya S1 sebanyak 78 orang dengan persentase sebesar $65 \%$ dan responden yang jenis pendidikannya S2 sebanyak 13 orang dengan persentase sebesar 10,8\%. Data mengenai yang Berbelanja Online Selama 3 Bulan Terakhir 1-5 kali sebanyak 81 orang responden dengan persentase sebesar $67,5 \%$, responden yang Berbelanja Online Selama 3 Bulan Terakhir 6-10 kali sebanyak 26 orang responden dengan persentase sebesar 21,7\% dan responden yang Berbelanja Online Selama 3 Bulan Terakhir lebih dari 10 kali sebanyak 13 orang responden dengan persentase sebesar $10,8 \%$.

Analisis regresi ganda digunakan untuk menguji apakah persepsi harga, promosi dan kualitas layanan memiliki pengaruh terhadap keputusan pembelian. Hasil seluruh uji asumsi yang dilakukan telah terpenuhi yang terdiri dari uji normalitas, uji multikolinieritas dan uji heteroskedastisitas. Taraf signifikansi yang digunakan dalam penelitian ini adalah $5 \%$. 


\section{HASIL DAN PEMBAHASAN}

Tabel 1

Hasil Uji Hipotesis

\begin{tabular}{|c|c|c|c|c|c|c|}
\hline \multicolumn{2}{|c|}{ Model } & \multicolumn{2}{c|}{$\begin{array}{c}\text { Unstandardized } \\
\text { Coefficients }\end{array}$} & Standardized Coefficients & \multirow{2}{*}{ Sig. } \\
\cline { 3 - 7 } \multicolumn{2}{c|}{} & B & Std. Error & Beta & & \\
\hline \multirow{4}{*}{1} & (Constant) & $-2,923$ & 1,637 & & $-1,786$ &, 077 \\
\cline { 2 - 7 } & Persepsi_Harga &, 205 &, 084 &, 191 & 2,431 &, 017 \\
\cline { 2 - 7 } & Brand_Image &, 472 &, 108 &, 335 & 4,375 &, 000 \\
\cline { 2 - 7 } & Pengalaman Belanja Online &, 459 &, 116 &, 352 & 3,971 &, 000 \\
\hline
\end{tabular}

Hasil pengujian hipotesis pertama menunjukan bahwa terdapat pengaruh secara positif variabel persepsi harga terhadap purchase decision produk fashion pada generasi milenial Jakarta. Hasil penelitian ini seusai dengan Penelitian yang dilakukan oleh Hastuti et al. (2018) dan Lalujan et al. (2016). Hasil pengujian hipotesis kedua menunjukan terdapat pengaruh secara positif variabel citra merek terhadap purchase decision produk fashion pada generasi milenial Jakarta. Hasil penelitian ini seusai dengan penelitian yang dilakukan oleh Foster (2016), Harwani dan Pradita (2017) serta Djatmiko dan Pradana (2016). Hasil pengujian hipotesis ketiga menunjukan bahwa terdapat pengaruh secara positif variabel pengalaman belanja online terhadap purchase decision produk fashion pada generasi milenial Jakarta. Hasil penelitian ini seusai dengan penelitian yang dilakukan oleh Kartika dan Ganarsih (2019).

\section{KESIMPULAN DAN SARAN}

Berdasarkan hasil penelitian mengenai pengaruh Persepsi harga, Citra Merek, Pengalaman Belanja Online terhadap keputusan pembelian maka dapat disimpulkan sebagai berikut: Kesimpulan dari hasil penelitian adalah sebagai berikut: Terdapat pengaruh positif persepsi harga terhadap purchase decision. Terdapat pengaruh positif citra merek terhadap purchase decision. Terdapat pengaruh positif pengalaman belanja online terhadap purchase decision.

Berkaitan dengan hasil penelitian, maka dapat disampaikan beberapa implikasi manajerial yang bisa diterapkan oleh perusahan produk fashion. Manajemen perlu memperhatikan harga yang merupakan bahan dasar konsumen sebagai pembanding dengan harga produk pesaing, maka perlunya menganalisis kembali apakah harga yang ditawarkan ataupun penetapan harga cukup kompetitif dibandingkan pesaing. Proses pengacuan penetapan harga dapat dibantu melalui survei pasar lebih lanjut apakah produk perusahaan memiliki harga sesuai dengan kualitas, sesuai dengan manfaat dan lebih kompetitif dibandingkan dengan pesaing dan penentuan harga agar lebih tepat sasaran dengan melakukan survei karakter konsumen seperti apakah harga yang diajukan untuk merebut pasar maka dengan penawaran harga rendah demi merebut pasar, dalam posisi masih untuk promosi dengan maksud mendorong penjualan produk. Hal-hal yang dapat dilakukan diantaranya semakin meningkatkan pemahaman konsumen terhadap keunggulan produk perusahaan melalui promosi ataupun pelayanan solusi oleh penjual agar dapat menyesuaikan kebutuhan konsumen serta meningkatkan keunggulan bersaing dengan menonjolkan keunggulan pada bidang fashion .

\section{DAFTAR PUSTAKA}

Aritonang, L. R. (2014). Metode penelitian bisnis (4th ed.). Universitas Terbuka.

Djatmiko, T., \& Pradana, R. (2016). Brand image and product price; Its impact for Samsung smartphone purchasing decision. Procedia - Social and Behavioral Sciences, 219, 221227. https://doi.org/10.1016/j.sbspro.2016.05.009

Foster, B. (2016). Impact of brand image on purchasing decision on mineral water product "Amidis" (Case study on Bintang trading company). American Research Journal of Humanities and Social Sciences, 2(1), 1-11. https://doi.org/10.21694/2378-7031.16023 
Harwani, Y., \& Pradita, S. R. (2017). Effect of brand image and perceived price towards purchase decision in Kentucky Fried Chicken (KFC). Journal of Marketing and Consumer Research, 36(9), 13-23.

https://www.iiste.org/Journals/index.php/JMCR/article/view/37548/38631

Hastuti, A. W., Pancawati, Y., \& Surana, I. N. (2018). The abundance and spatial distribution of plankton communities in Perancak Estuary, Bali. IOP Conference Series: Earth and Environmental Science, 176(1), 1-9. https://doi.org/10.1088/1755-1315/176/1/012042

Kartika, M., \& Ganarsih, R. L. (2019). Analisis e-WOM, online shopping experience dan trust terhadap keputusan pembelian dan kepuasan konsumen e-Commerce Shopee pada mahasiswa pascasarjana Universitas Riau. Jurnal Tepak Manajemen Bisnis, 11(2), 289307. https://jtmb.ejournal.unri.ac.id/index.php/JTMB/article/download/7439/6503

Kaura, V. (2012). A link for perceived price, price fairness and customer satisfaction. Pacific Business Review International, 5(6), 84-88.

Kotler, P., \& Keller, K. L. (2012). Manajemen pemasaran (12th ed.). Erlangga.

Lalujan, D. I. O., Pengemanan, S. S., \& Tumbuan, W. J. F. A. (2016). Analyzing the influence of brand image, perceived price and perceived quality on consumer buying decision of low cost green car (Case study of: Astra Toyota Agya at Manado). Jurnal Berkala Ilmiah Efisiensi, 16(04), 145-155.

Michaud Trevinal, A., \& Stenger, T. (2014). Toward a conceptualization of the online shopping experience. Journal of Retailing and Consumer Services, 21(3), 314-326. https://doi.org/10.1016/j.jretconser.2014.02.009

Peter, P. J., \& Olson, J. C. (2014). Perilaku konsumen dan strategi pemasaran (9th ed.). Salemba Empat.

Suhaily, L., \& Darmoyo, S. (2017). Effect of product quality, perceived price and brand image on purchase decision mediated by customer trust (study on japanese brand electronic product). Jurnal Manajemen, 21(2), 179-194.

https://doi.org/10.24912/jm.v21i2.230 